limited resources firm evidence is required for an informed decision.

In the absence of better methods for evaluating cervical cytology other possible sources of evidence have been eagerly examined. Foremost among these is the extensive cytology service in British Columbia. This began sooner (in 1949) and quickly became more extensive than elsewhere in the world, so that $80 \%$ of women are now estimated to have been screened. ${ }^{6}$ If screening is effective, it would be reasonable to expect mortality rates to be lower in that province than elsewhere in Canada. No such suggestion could be found when these rates were analysed up to $1965 .^{7}$ However, standardized mortality rates at ages 45-64 have recently been slightly lower there than in the rest of Canada. ${ }^{8}$ Though the differences are not dramatic, they nevertheless provide the first suggestion of an effect of cervical screening on a population's mortality rates.

Great interest is bound to be directed over the next few years towards Canada to see if these inter-province differences in mortality become more pronounced, and also towards the outcome of current studies. It is to be hoped that support will be given to the appeal by A. I. Spriggs ${ }^{4}$ for details of cases of positive smears in women who then refuse surgical intervention. The opportunities for contacting during pregnancy or the puerperium those women at high risk who tend to elude the screeners deserve further exploration.

As with B.C.G. vaccination, anticoagulant therapy, and coronary care units, experience of screening by cervical cytology has underlined the necessity of looking ahead to the best ways of evaluating a new therapy. Otherwise, as E. G. Knox ${ }^{9}$ stated in 1966, equivocation will be encouraged by uncertainty about whether a given enterprise which diverts skilled manpower from other worthwhile work is adequately justified or whether there is a failure to carry out a measure which should be more widely applied. In either event the consequence is to be costed in terms of lives.

1 Department of Health and Social Security, Annual Reports of ChieJ Medical Officer of Health, London, H.M.S.O.

2 Schneider, J., and Twiggs, L. B., Obstetrics and Gynaecology, 1972, 40, 851

3 Wakefield, J., Yule, R., Smith, A., and Adelstein, A. M., British Medica fournal, 1973, 2, 142.

4 Spriggs, A. I., Lancet, 1971, 2, 599.

5 Taylor, N. R. W., and Wynne Griffith, G., in Portfolio for Health, 2, ed. G. McLachlan. London, Nuffield Provincial Hospitals Trust, O.U.P., 1973.

6 Boyes, D. A., in Symposium of British Society for Clinical Cytology, 26 September 1972.

7 Ahluwalia, H. S., and Doll, R., British Fournal of Preventive and Social Medicine, 1968, 22, 161

${ }^{8}$ Kinlen, L. J., and Doll, R., British Fournal of Preventive and Social Medicine, 1973, 27, 146 .

Knox, E. G., in Problems and Progress in Medical Care, 2nd series, ed. G. McLachlan. London, Nuffield Provincial Hospitals Trust, O.U.P., 1966.

\section{Guardians of Ethics}

Two years ago the Chief Medical Officer wrote to the then president of the Royal College of Physicians of London and put some questions to him about the supervision of the ethics of clinical research in hospitals and other institutions. The college set up a committee to consider the matter, and its report is published this week. ${ }^{1}$ It discusses the composition of ethical committees, the kind of investigations that should be referred to them, and some of the ethical questions that may arise.
For some years variously composed local committees have existed to advise clinicians on the ethical propriety of investigations they wish to carry out on patients. Hospital boards have a duty to see that unethical practices do not occur, and the public has a right to be satisfied likewise. The medical profession too must be vigilant in guarding its reputation from the harm that could come to it if unethical conduct went unchecked. But, though the overwhelming majority of doctors who do clinical research are entirely scrupulous in the treatment of their patients, they know that difficult questions of ethics can legitimately arise. For ethical conduct is not controlled by regulations set out in a lawyer's convoluted if unambiguous phraseology. It is much more aptly summed up in the words from the World Medical Association's Declaration of Geneva, "The health of my patient will be my first consideration," and no physician with any concern for his professional standards would ever depart from that injunction. Consequently the first object of any ethical committee should be to act not as a policeman but as an adviser. According to the college's report its members should be "experienced clinicians with a knowledge of clinical research investigation and in addition there should be a lay member," and this proposed composition may be endorsed. The lay member could bring a refreshing outside view to the committee's discussions and would need to be a man-or woman-of some personality to stand up to the doctors.

In being able to bring his proposals to an informed and experienced committee a clinical investigator should be able to feel that his project is examined with the idea of improving rather than blocking it. But there must also be occasions when such committees are nothing less than guardians of public health or safety. Work which in the view of at least some editors fails to conform to acceptable ethical standards does get carried out and written up. A recent editorial in the Archives of Disease in Childhood, ${ }^{2}$ for instance, states "we have occasionally asked an author to excise the unethical component of a piece of work." Whether, if that is done, the result should be published is a matter of opinion. Again, the B.M.F. cannot be alone in rejecting-though rarely-a paper on ethical grounds. The mere existence of the lapses from what individual editors and their advisers believe to be proper standards indicates that both control and education must be part of the work that ethical committees carry out.

It is important too that these committees should not work in isolation, for judgements on ethical matters have a large subjective component just as they do on some clinical matters, such as termination of pregnancy. Free discussion of the problems they must face is particularly desirable if only to ensure that wildly different standards do not prevail in different hospital areas.

The report is right to advocate that all clinical research, including trials of drugs approved under the Medicines Act and teaching demonstrations on students, should be submitted for approval to the ethical committee. The only exception is to be the treatment of an individual patient outside the research context. Therefore some thought should be given to the setting up of these committees in areas or for hospitals at present lacking them. Possibly a joint committee of the colleges could survey the situation and give some advice on where and how they might be appointed, for the best way of selecting their members is not self-evident.

\footnotetext{
Royal College of Physicians of London, Committee on the Supervision of the Ethics of Clinical Research Investigations in Institutions, Report, July 1973 (published 30 November 1973) 2 Archives of Disease in Childhood, 1973, 48, 751.
} 